\title{
Establishment of a Functional Genomics Platform for Leifsonia xyli subsp. xyli
}

\author{
Stevens M. Brumbley, ${ }^{1,2}$ Lars A. Petrasovits, ${ }^{1}$ Rachel M. Murphy, ${ }^{1,2}$ Roland J. Nagel, ${ }^{1}$ Judith M. Candy, \\ and Scott R. Hermann ${ }^{1,2}$ \\ ${ }^{1}$ BSES Limited, David North Plant Research Centre, 50 Meiers Rd, Indooroopilly, Queensland, 4068, Australia; ${ }^{2} \mathrm{CRC}$ \\ Tropical Plant Protection, University of Queensland, Brisbane, Queensland, 4072, Australia
}

Submitted 23 June 2003. Accepted 29 September 2003.

Leifsonia xyli subsp. xyli, the causal agent of ratoon stunting disease in sugarcane, is a xylem-limited, nutritionally fastidious, slow growing, gram-positive coryneform bacterium. Because of the difficulties in growing this bacterium in pure culture, little is known about the molecular mechanisms of pathogenesis. Currently, the genome sequence of L. xyli subsp. xyli is being completed by the Agronomical and Environmental Genomes group from the Organization for Nucleotide Sequencing and Analysis in Brazil. To complement this work, we produced 712 Lxx::Tn4431 transposon mutants and sequenced flanking regions from 383 of these, using a rapid polymerase chain reaction-based approach. Tn4431 insertions appeared to be widespread throughout the $L$. xyli subsp. xyli genome; however, there were regions that had significantly higher concentrations of insertions. The Tn4431 mutant library was screened for individuals unable to colonize sugarcane, and one noncolonizing mutant was found. The mutant contained a transposon insertion disrupting two open reading frames (ORF), one of which had homology to an integral membrane protein from Mycobacterium leprae. Sequencing of the surrounding regions revealed two operons, pro and $c y d$, both of which are believed to play roles in disease. Complementation studies were carried out using the noncolonizing Lxx::Tn4431 mutant. The noncolonizing mutant was transformed with a cosmid containing $40 \mathrm{kbp}$ of wild-type sequence, which included the two ORF disrupted in the mutant, and several transformants were subsequently able to colonize sugarcane. However, analysis of each of these transformants, before and after colonization, suggests that they have all undergone various recombinant events, obscuring the roles of these ORF in $L$. xyli subsp. xyli pathogenesis.

Ratoon stunting disease (RSD) of sugarcane is caused by Leifsonia xyli subsp. xyli (Davis et al. 1980), a gram-positive coryneform, xylem-limited bacterial pathogen (Kao and Damann 1980). RSD is the result of vascular plugging that causes general stunting (Kao and Damann 1980), but otherwise,

\section{Corresponding author: S. M Brumbley: sbrumbley@bses.org.au}

The nucleotide sequence data is available in the GenBank database under accession numbers AY298956, CG410907 to CG411280, and CG415043 to CG415052.

* The $\boldsymbol{e}$-Xtra logo stands for "electronic extra" and indicates the HTML abstract available on-line contains a supplemental table not included in the print edition.
RSD has no reliable external symptoms (Gillaspie and Teakle 1989). It is currently unknown whether this plugging is bacterially produced, whether it is a plant defense response, or if it is a combination of products from both $L$. xyli subsp. xyli and the sugarcane plant. RSD is the most economically important pathogen of sugarcane worldwide, with losses reported ranging from less than 5\% to exceeding 30\% (Bailey and Bechet 1997; Koike et al. 1982; Steib and Chilton 1968). The effects of the disease and the consequent losses depend primarily on water availability (McDougall et al. 1948; Rossler 1974) and cultivar susceptibility (Giglioti et al. 1999; Wismer 1971).

L. xyli subsp. xyli was originally described in the genus Clavibacter (Davis et al. 1984), based on phenotypic characteristics, but recently was reviewed and placed in the genus Leifsonia (Evtushenko et al. 2000), based on rRNA gene analysis. It is nutritionally fastidious and grows extremely slow in culture, taking up to four weeks for single colonies visible to the naked eye to appear on complex solid media and two weeks for growth to mid-log phase in liquid culture. As a result, there has been little molecular work on L. xyli subsp. xyli. Recently, the Agronomical and Environmental Genomes (AEG) program in the state of São Paulo, Brazil, a subprogram of the Organization for Nucleotide Sequencing and Analysis, began sequencing and annotation of a Brazilian isolate of $L$. xyli subsp. xyli. Complementary to this work, 712 L. xyli subsp. xyli transposon mutants were generated (Brumbley et al. 2002) using the transposon $\operatorname{Tn} 4431$. Tn4431 is a derivative of Tn1721 (Shaw et al. 1988), a transposon structurally similar to the Tn3 family of transposons (Mahillon and Chandler 1998) and carries a promoterless lux operon from Vibrio fischeri. Luciferase studies on these $L x x: \operatorname{Tn} 4431$ mutants indicated that $99 \%$ of the mutants had insertions into or in frame with functional genes (Brumbley et al. 2002). In this report, we discuss the development of a high throughput polymerase chain reaction (PCR)-based screening method to identify insertion points of the transposon Tn4431 into the L. xyli subsp. xyli genome. We also screened the Lxx::Tn4431 mutants for their ability to colonize sugarcane and have identified two open reading frames (ORF) that may be involved in pathogenicity.

\section{RESULTS}

Transposon mutagenesis and mapping of insertion sites.

Of the 712 Lxx::Tn4431 mutants originally constructed, 383 flanking sequences were PCR-amplified and sequenced using either of the Tn4431 end-specific primer/probe combinations. Amplification of $L x x:$ Tn4431 DNA using the semispecific PCR and 70 cycles of amplification resulted in one or occasionally 
more DNA products (Fig. 1A). The number of specific products did not always equal the number of DNA products amplified, and the specific product was not always dominant (Fig. 1B). PCR products amplified ranged in size from approximately 70 bp to $4 \mathrm{kbp}$. A total of 251 flanking DNA sequences could not be amplified with the primers used in this study, while another 78 flanking DNA sequences were amplified but could not be sequenced.

Positively hybridizing products (Fig. 1B) were purified and directly sequenced with the respective oligonucleotide probes bss7 or bs17. PCR reactions that produced two or more hybridizing products were always the result of the single primer binding at multiple sites downstream from the transposon insertion. Interestingly, when the sequences were compared against those of the AEG L. xyli subsp. xyli genome project, a 5-bp deletion at the target site was always associated with insertion of $\operatorname{Tn} 4431$.

Functional classification was assigned to the 383 flanking sequences, using categories defined by Bolotin and associates (1999) (Fig. 2). Of these, 44\% were not similar to any other protein or putative protein currently available (Blast-X). A further $12 \%$ of insertions lay within transposon or phagerelated genes, while $10 \%$ had matches to hypothetical proteins from other members of the class Actinomycetes. The remaining

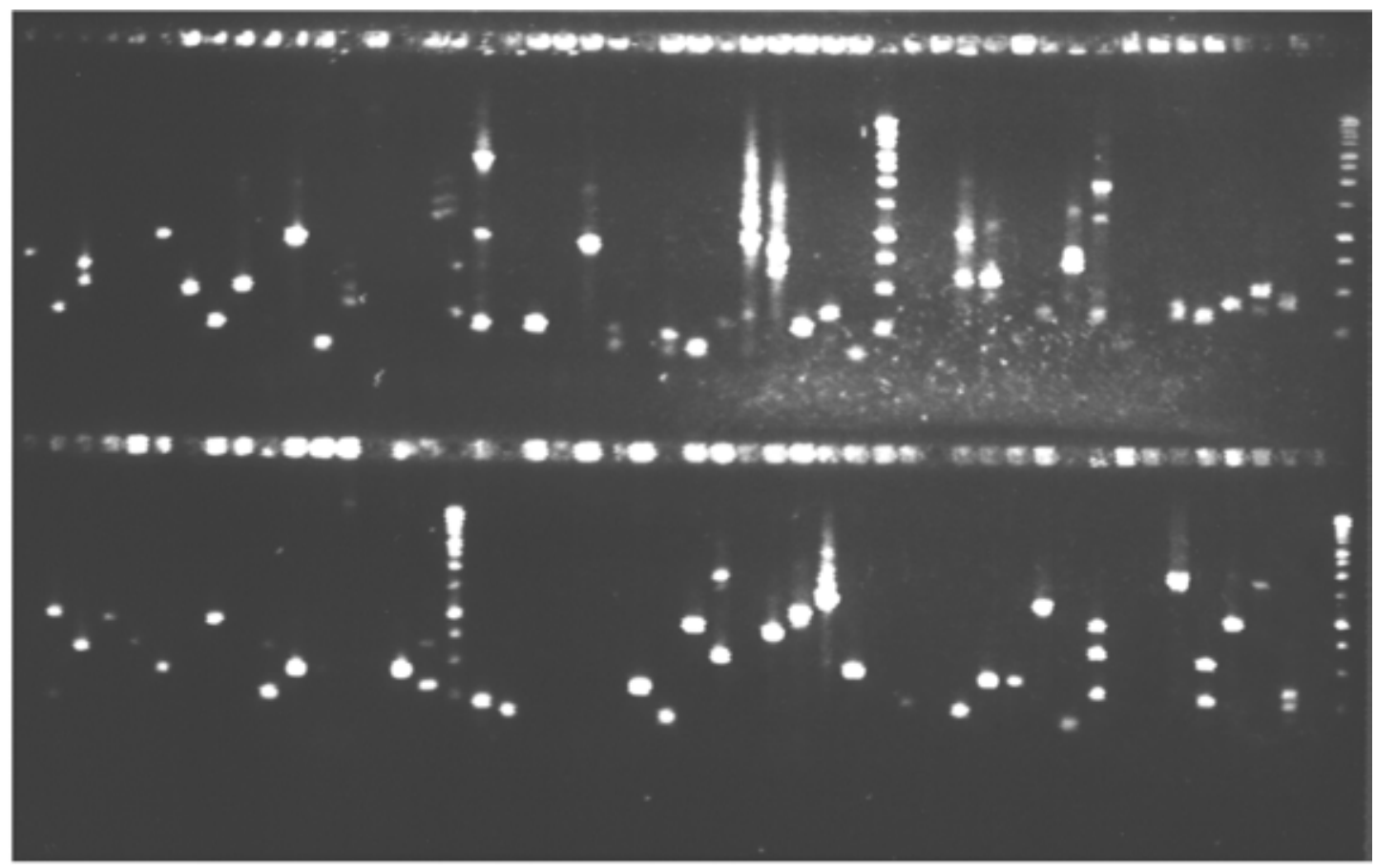

A

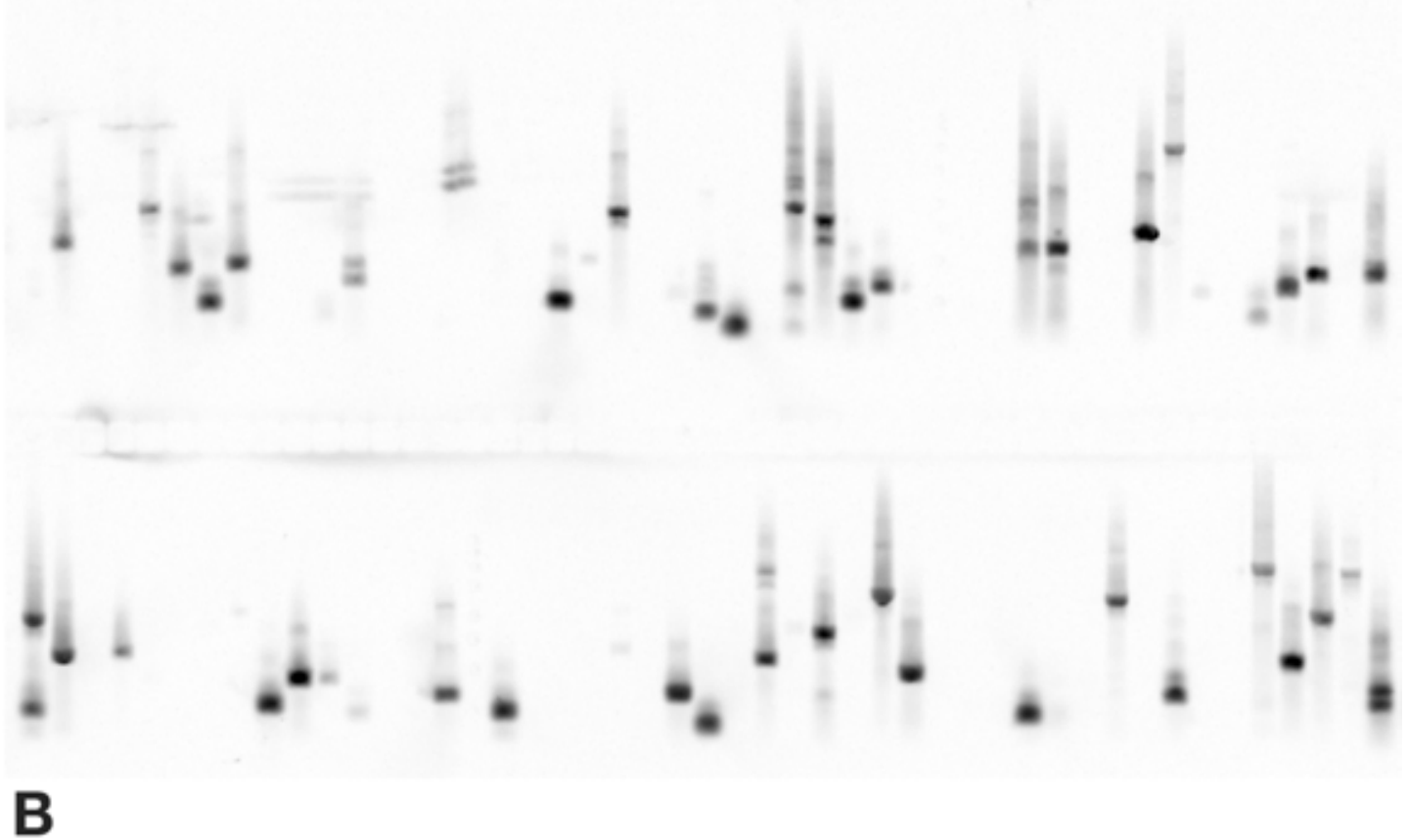

Fig. 1. Semispecific polymerase chain reaction amplification products of Leifsonia xyli subsp. xyli Tn4431 mutants using the bss7RM1 primer. A, Agarose gel electrophoresis with ethidium bromide stain under UV light. B, Southern hybridization of blotted products from A probed with the ${ }^{33}$ P- $\gamma$-ATP labeled primer bss7. 
sequences (34\%) were distributed across the other categories, with most insertions occurring in genes involved in energy metabolism (Fig. 2). Although there is currently insufficient $L$. xyli subsp. xyli sequence data to elucidate Tn4431 distribution across the entire genome, there is evidence that insertion has occurred nonrandomly. Of the 383 Tn4431 mutants sequenced, $54 \%$ of insertions were in regions already containing another transposon insertion (determined by sequence overlap or Blast-
X) (Fig. 2). Importantly, nearly all of these sequences had different insertion sites, indicating the insertion events were unique.

\section{Isolation of mutants unable to colonize sugarcane.}

To screen the $712 L x x:$ Tn4431 mutants for loss of pathogenicity, inoculations in triplicate for each of the mutants was performed, and after approximately three months, the plants

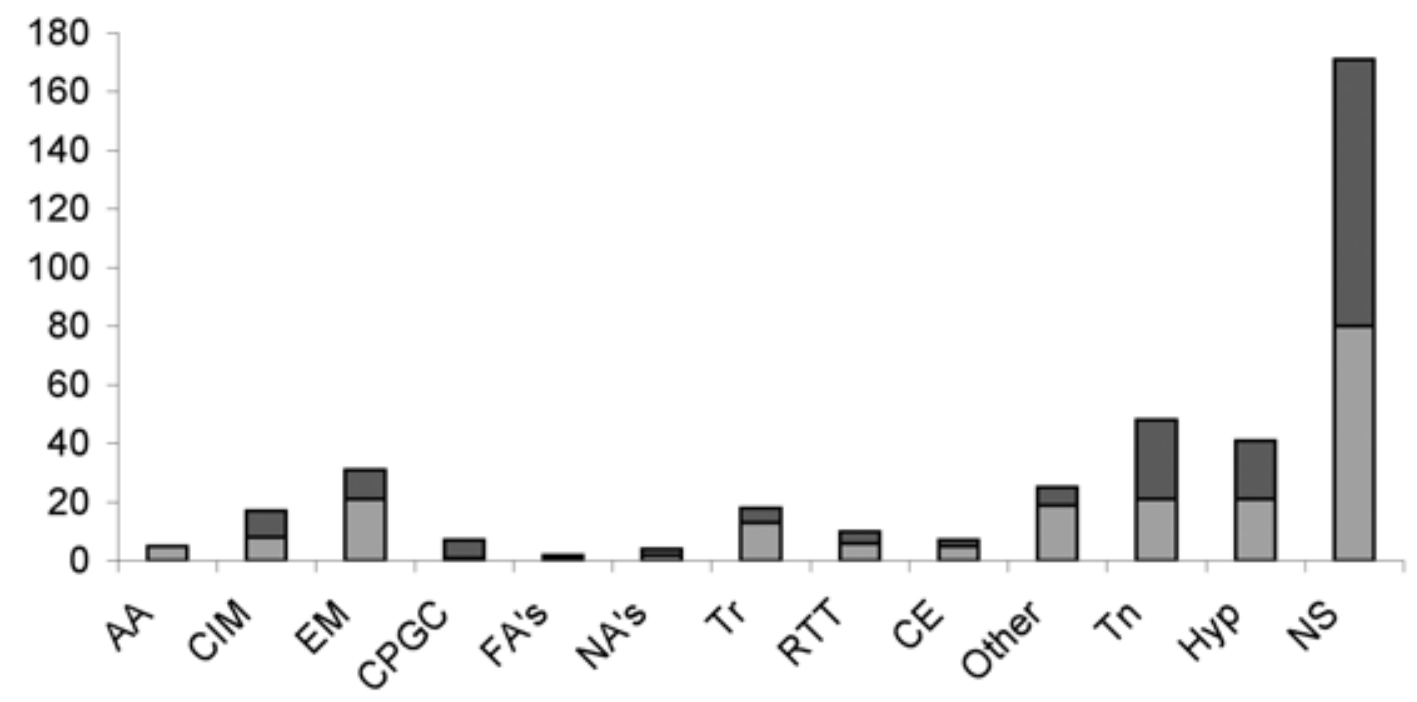

\section{gene functional classification}

Fig. 2. Putative functional classification of the flanking sequences identified in this study. All flanking regions were analyzed for matches using Blast-X and then were assigned a functional classification based on the work of Bolotin and associates (1999). The total number of sequences within each category is shown by total bar height. The number of sequences found to have a single Tn 4431 insertion is represented by the lower section of each bar. The upper section of each bar shows the number of sequences found to have multiple insertions, although not necessarily at the exact same point along the sequence. Similarities within the no similarity (NS) category were determined using alignment (ContigExpress; InforMax Inc., Frederick, MD, U.S.A.) AA = aminoacid biosynthesis; CIM = central intermediary metabolism; EM = energy metabolism; CPGC = biosynthesis of cofactors, prosthetic groups, and carriers; FA's = fatty acid and phospholipid metabolism; NA's = purines, pyrimidines, nucleosides, and nucleotides; $\operatorname{Tr}=$ transport and binding proteins; RTT = replication, transcription, and translation; $\mathrm{CE}=$ cell envelope; Other $=$ unassigned functions; $\mathrm{Tn}=$ transposon and phage related functions; Hyp $=$ hypothetical; and NS = no similarity.

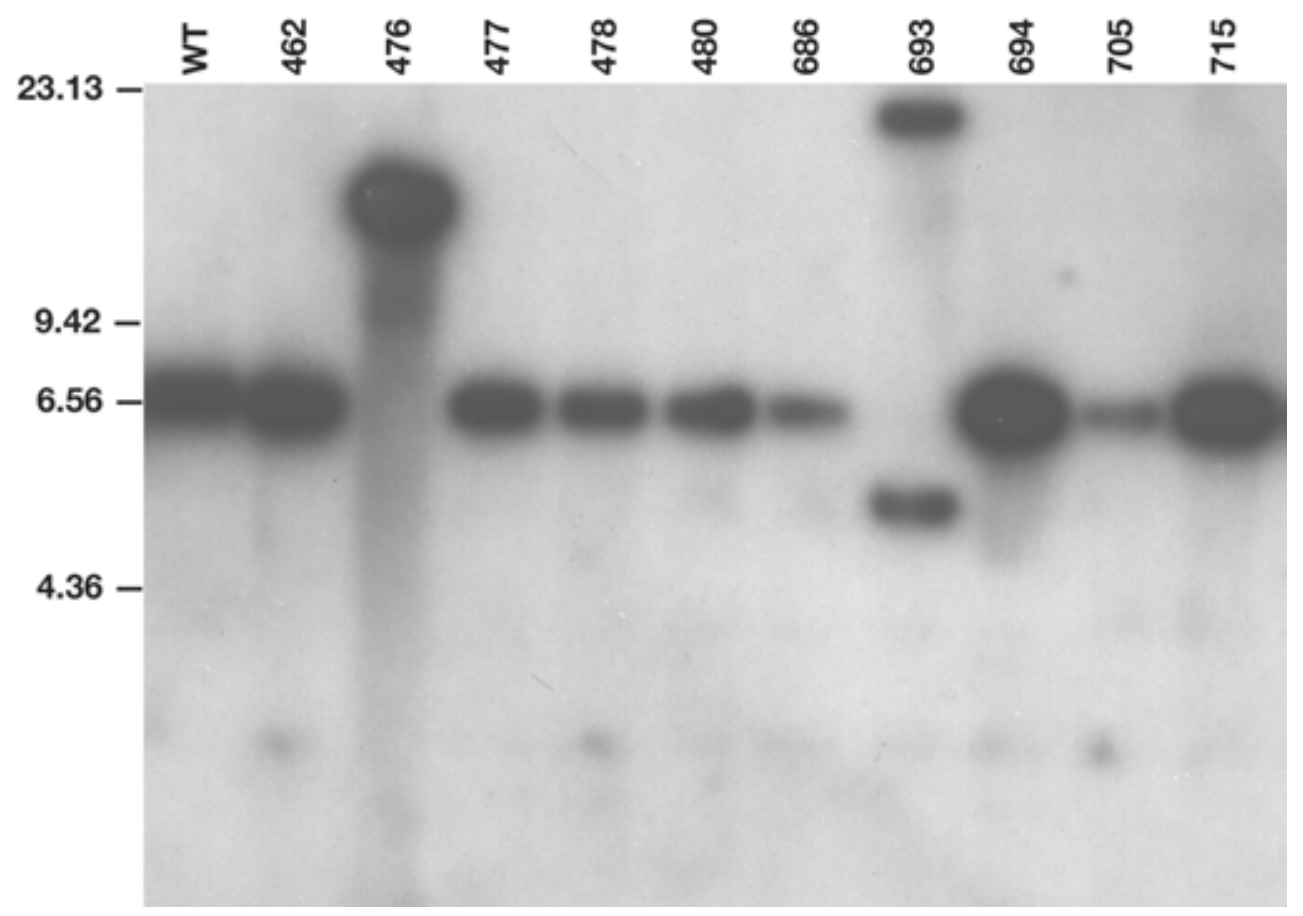

Fig. 3. Southern hybridization confirming the site of transposon insertion. Total genomic DNA from Leifsonia xyli subsp. xyli wild-type and Tn4431 mutants was digested with PstI. The inverse polymerase chain reaction product amplified from mutant QPF110-476 was used as a probe. 
were harvested, and the presence of $L . x y l i$ subsp. xyli wildtype and $L x x: \operatorname{Tn} 4431$ mutants was determined. Only one Lxx::Tn4431 mutant, QPF110-476, failed to colonize in this initial screen. To confirm this, QPF110-476 was inoculated onto sugarcane plants four additional times, twice in replicates of 15 . Colonization was not detected in any of these inoculations.

\section{Identification of the genomic region containing transposon insertion and complementation.}

The QPF110-476 DNA flanking the transposon insertion could not be amplified using semispecific PCR. However, a $1.3-\mathrm{kbp}$ fragment was amplified using inverse PCR. This was cloned, and its identity as flanking DNA was confirmed by Southern hybridization (Fig. 3). The Tn4431 insertion disrupted two potential ORF in opposite directions (Fig. 4). The larger of these two ORF (Blast-X) was similar to an integral membrane protein from Mycobacterium leprae (E: 2e-18), although we found no evidence of similar domains using PROSITE (Gattiker et al. 2002). The ORF was also similar to a $\mathrm{Zn}$-dependent protease (E: 5e-6) and a peptidase (4e-6) from Corynebacterium glutamicum. Similar hypothetical proteins with unknown function were identified in other members of the class Actinomycetes, including Thermobifida fusca (E: 1e-31), Mycobacterium tuberculosis (E: 2e-24), and Streptomyces coelicolor (E: 9e-7) (Fig. 5). From a multiple alignment, it appears likely that this ORF has a Val start codon and encodes a hypothetical protein of 314 amino acids. The smaller of the disrupted ORF (orf24) did not appear to have any similarity to any other public DNA or protein sequences.

To isolate the wild-type gene and to study regions flanking the two ORF, a cosmid library of a wild-type L. xyli subsp. xyli (QPF110) was constructed. The inverse PCR product was used as a probe, and two unique cosmid clones were identified, one of which (pLB1C2) was shotgun cloned and a total of 11,236 bp was sequenced. Analysis of this region revealed strong homology to the pro operon of M. tuberculosis and to cytochrome oxidase subunits I and II (Fig. 4). Interestingly, three other mutants contained $\mathrm{Tn} 4431$ insertions within this 11-kbp region; however, these were all still able to colonize sugarcane. Complementation studies were carried out to demonstrate whether these regions were able to restore the ability of mutant QPF110-476 to colonize sugarcane. The mutant was trans- formed with cosmid $\mathrm{pLB} 1 \mathrm{C} 2$ to generate kanamycin-resistant transformants 476-C2a, 476-C2b, 476-C2c, 476-C2d, and 476$\mathrm{C} 2 \mathrm{e}$. The transformants were analyzed for the presence of the wild-type and mutant ORF by Southern hybridization (Fig. 6A) and PCR (Fig. 6B). In summary (Table 1), the wild-type ORF originally carried on the cosmid could be detected by PCR in all the transformants except 476-C2a, while the cosmid could only be detected in $476-\mathrm{C} 2 \mathrm{a}, 476-\mathrm{C} 2 \mathrm{~b}$, and $476-\mathrm{C} 2 \mathrm{c}$ by Southern hybridization. Transformant $476-\mathrm{C} 2 \mathrm{~d}$ appeared to lack the larger of the hybridizing bands, suggesting part of this region had been lost, while transformant 476-C2e was no longer resistant to tetracycline.

After three months, fibrovascular fluid was extracted from plants and spread onto kanamycin-containing filters, and a single bacterial colonies were isolated. The presence of $\operatorname{Tn} 4431$ in each of these ex planta bacteria was confirmed by a mutantspecific PCR amplification (Fig 6B). Of the five transformants, only 476-C2d was unable to colonize sugarcane. Interestingly, the wild-type ORF could not be detected in any of the transformants.

\section{DISCUSSION}

To complement the L. xyli subsp. xyli genome sequencing effort carried out by the AEG group, we have produced $712 \mathrm{~L}$. xyli subsp. xyli transposon mutants and have sequenced flanking regions from more than half of them. The 712 L. xyli subsp. xyli mutants were generated using a transformation and transposon mutagenesis system developed by Brumbley and associates (2002). To identify the Tn4431 insertion sites for each of the mutants, a rapid, single primer technique based on that of Hermann and associates (2000) was developed. Primers were designed to amplify outward from each end of Tn4431. Template DNA was derived from washed $L x x: \operatorname{Tn} 4431$ frozen stocks and required no further isolation, purification, or modification. Under the amplification conditions used, these primers were able to specifically amplify the Tn4431 end sequence in $65 \%$ of cases. This percentage could probably be increased through the use of different amplification primers and conditions. Amplified products were directly sequenced using an internal primer. Given the fastidious nature of $L$. xyli subsp. $x y l i$, its extremely slow growth, and the difficulties encountered with purification of genomic DNA, this high-throughput

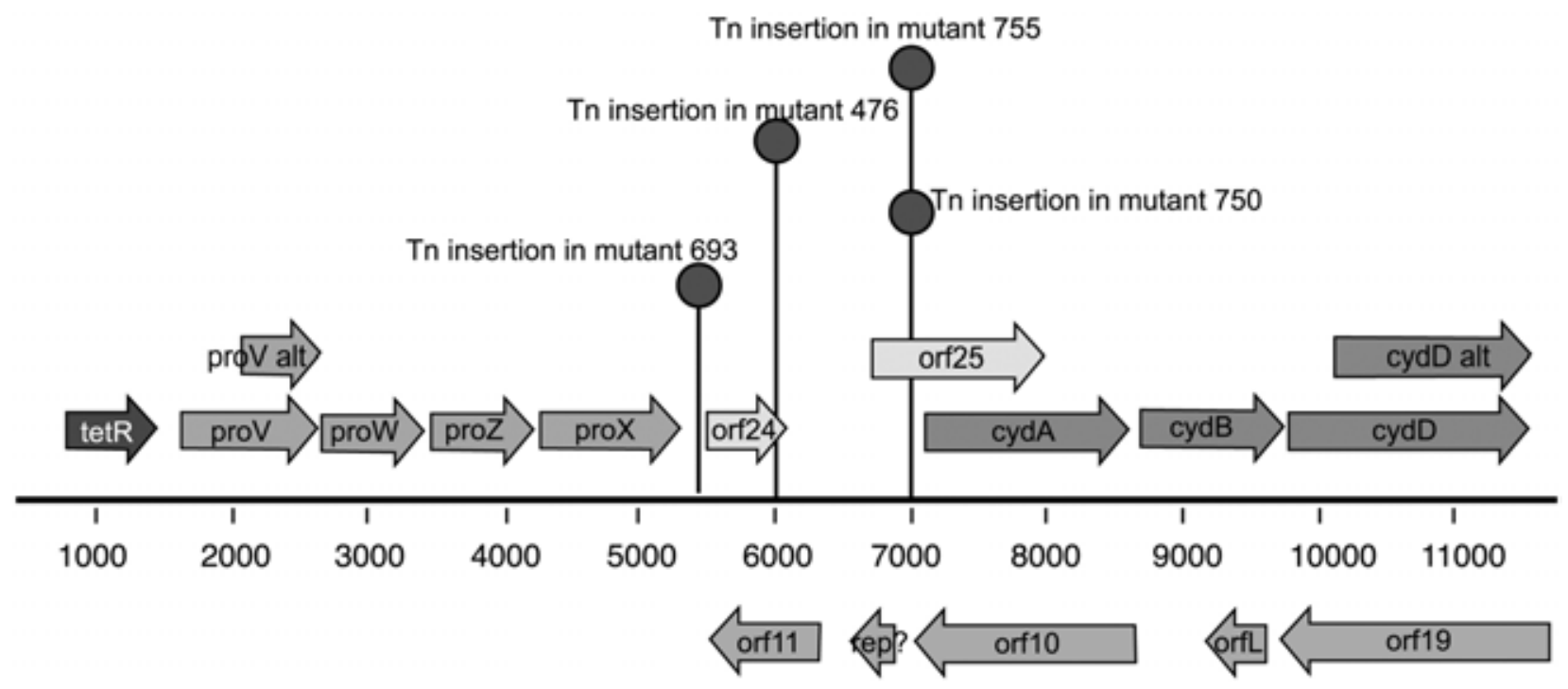

Fig. 4. Schematic drawing of 11,236 bp of Leifosonia xyli subsp. xyli sequence encompassing the pro VWZX and cyd ABD operons. The position of different Tn4431 insertions in various $L$. xyli subsp. xyli mutants is shown. orf = open reading frame, tetR $=$ transcriptional regulator of the tetR family, pro $=$ proline transport, and cyd $=$ cytochrome $d$ oxidase. 
technique provided a rapid alternative to either cloning or direct sequencing of the Tn4431 insertion sites.

As the L. xyli subsp. xyli genome sequence is not yet complete, it is impossible to examine the distribution of Tn4431 insertions across the genome. However, there is evidence that transposition was not completely random. In a 16-kbp contig (data not shown), we identified at least 19 individual Tn4431 insertions, which is 10 times higher than expected (assuming the transposon inserted in a random, nonbiased fashion). Similar results have been found with other Tn3 derivates in both yeast (Ross-Macdonald et al. 1999) and bacteria (Davies and Hutchison 1995).

Most insertions (171) were in sequences with no similarity to any other putative protein-encoding genes in the databases. The classes with the next highest hits (48 and 40) showed homology to transposon associated sequences and to hypothet- ical proteins from other members of the class Actinomycetes, respectively. Interestingly, over $50 \%$ of the flanking regions sequenced in these categories had multiple insertions, primarily in unique locations along the sequence. The remaining insertions (130) were scattered throughout various categories of genes, with most being in genes encoding i) energy metabolism (31\%), ii) transport and binding (18\%), and iii) central and intermediary metabolism (17\%) (Fig. 2).

One of the 712 Lxx::Tn4431 mutants was unable to colonize sugarcane. The Tn4431 insertion disrupted two ORF in opposite directions. The larger of these ORF had homology to an integral membrane protein from $M$. leprae and also to a protease and peptidase from $C$. glutamicum. Five transformants were produced containing $40 \mathrm{kbp}$ of wild-type sequence carried on a cosmid vector (pLB1C2), and four of these were able to colonize sugarcane (ex476-C2a, ex476-C2b, ex476-C2c, and ex476-

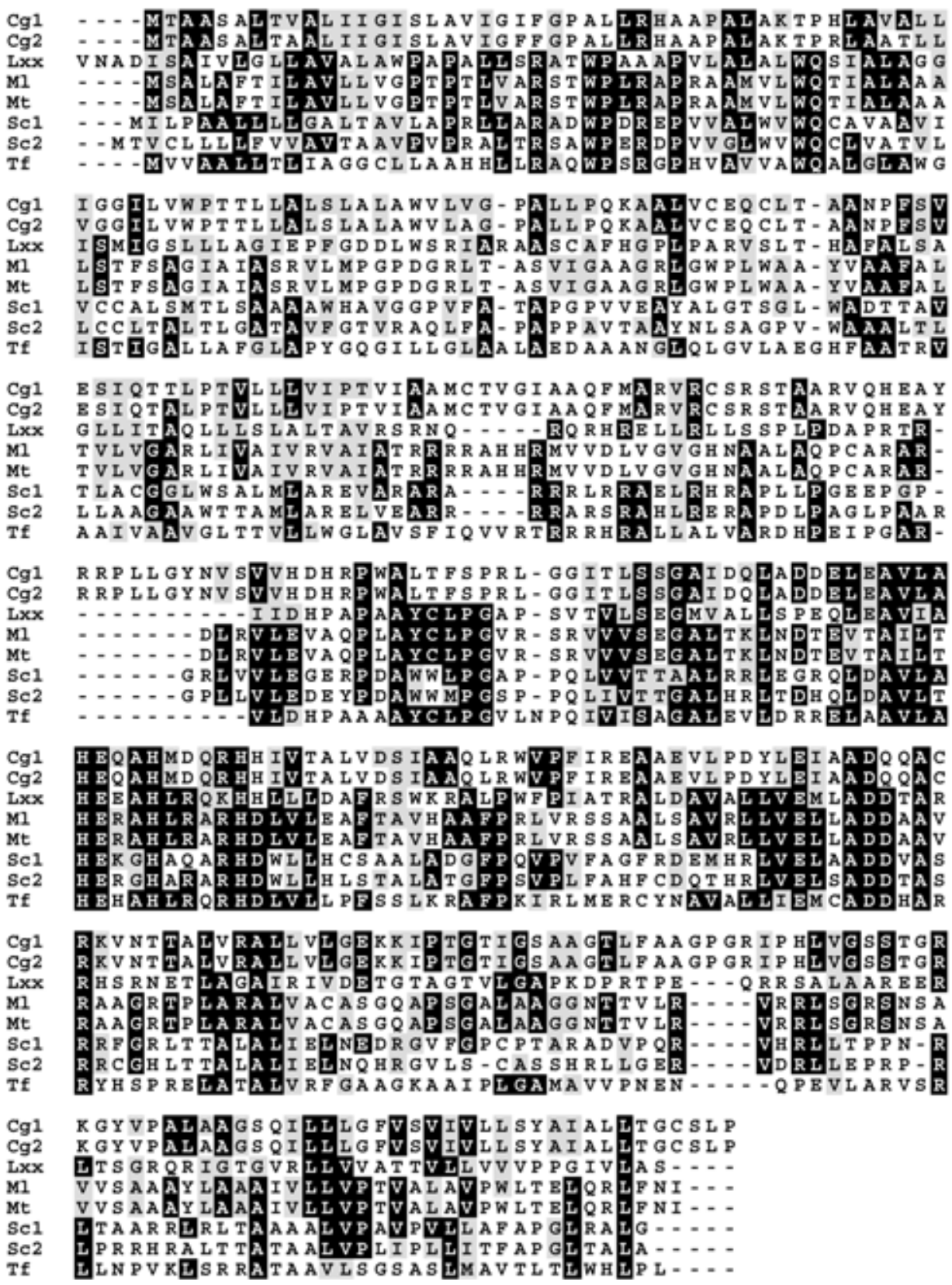

Fig. 5. Alignment of hypothetical proteins showing homology to one of the disrupted open reading frames (ORF) of QPF110-476. The translated product from the larger ORF is compared with putative proteins from: Corynebacterium glutamicum (Cg1, accession number NP_599272; Cg2, accession number AAL31539), Mycobacterium leprae (Ml, accession number NP_302376), M. tuberculosum H37Rv (Mt, accession number NP_216361), Streptomyces coelicolor A3 (Sc1, accession number NP_625395; Sc2, accession number NP_628741), and Thermobidida fusca (Tf, accession number ZP_00058818). Black boxes are identical residues, Gray boxes indicate conserved substitutions, and dashed lines indicate gaps. 
C2e). We performed Southern hybridizations and PCR analysis on these transformants before and after inoculation onto sugarcane. Before inoculation, two transformants appeared to retain the cosmid intact (476-C2b, and 476-C2c), while the other three appear to have undergone recombination events. Transformant 476-C2a may have lost part of the cosmid-borne wild-type ORF, as they could no longer be amplified by PCR, while both 476$\mathrm{C} 2 \mathrm{~d}$ and 476-C2e appear to have lost the cosmid but retained kanamycin resistance and the wild-type ORF, suggesting at least part of the cosmid has recombined with the genome. Furthermore, transformant $476-\mathrm{C} 2 \mathrm{~d}$ had also lost the larger of its hybridizing bands, which corresponds to part of the pro operon, and transformant 476-C2e had lost resistance to tetracycline, suggesting the recombination event occurred in this region. When the transformants were reisolated, the wild-type ORF could not be amplified from any of the transformants, suggesting that, during colonization or subsequent culture, further recombination events had occurred, resulting in loss of the wildtype ORF from 476-C2b, 476-C2c, and 476-C2e.

What role the disrupted ORF play in sugarcane colonization remains obscure. Mutant QPF110-476, which contained a single Tn4431 insertion, was unable to colonize sugarcane.

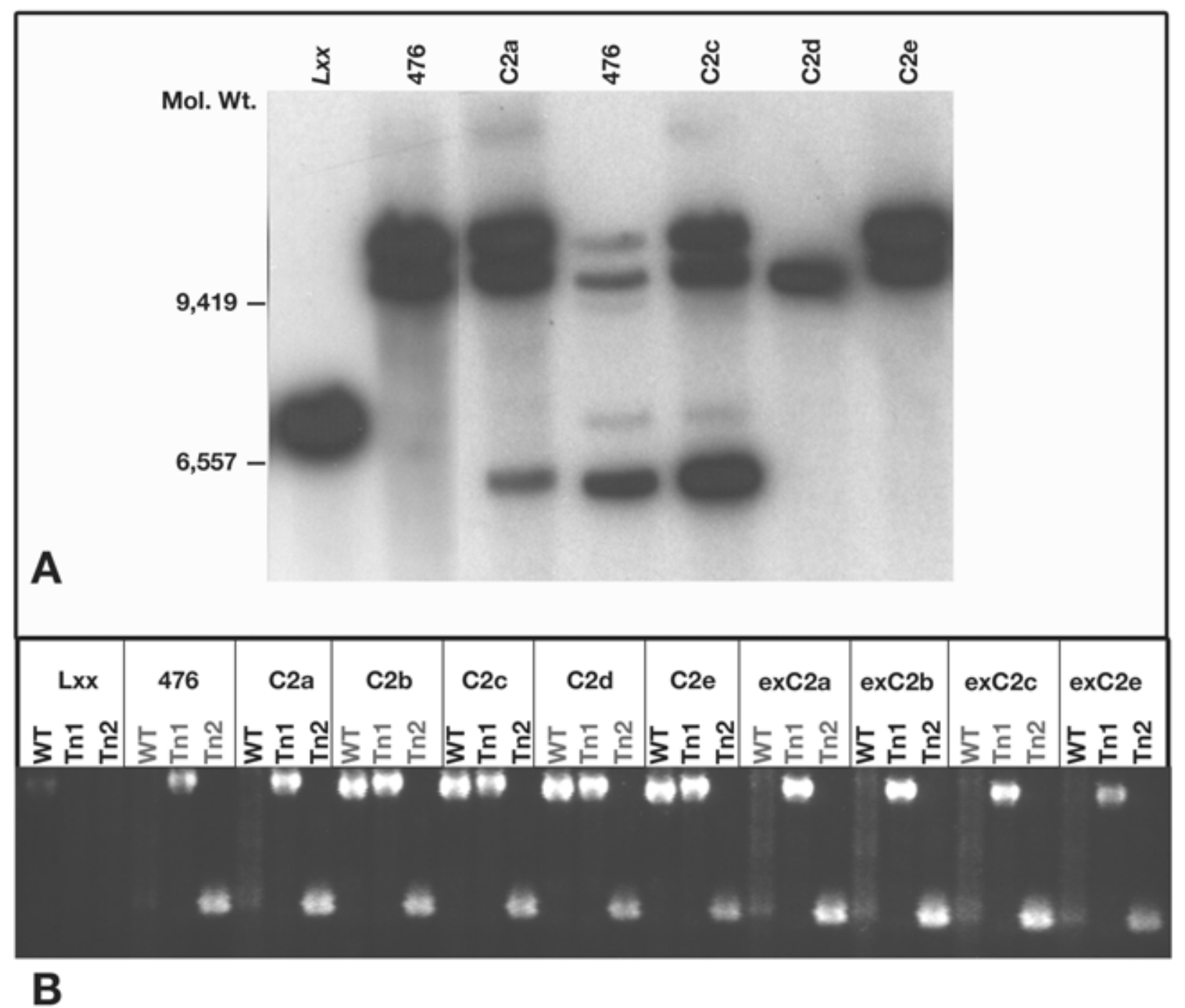

Fig. 6. Molecular analysis of Leifosonia xyli subsp. xyli transformants. A, Total genomic DNA from L. xyli subsp. xyli QPF110 (Lxx), QPF110-476 Tn4431 mutant (476), and transformants containing the complementary cosmid clone pLB1C2 (C2a to C2e) were probed with a $2.1-\mathrm{kbp}{ }^{32} \mathrm{P}-\mathrm{labeled}$ EcoRI/PstI fragment from DNA flanking the Tn4431 insertion. B, The presence of the wild-type and mutant open reading frames (ORF) were identified in L. xyli subsp. xyli transformants and ex planta isolates, using primer pairs ORF24F and ORF24R (WT), bs17RM1 and ORF24F (Tn1), and bss7RM1 and ORF24R (Tn2).

Table 1. Summary of characteristics of QPF110-476 transformants before and after colonization

\begin{tabular}{|c|c|c|c|c|c|c|c|c|c|}
\hline Characteristics & 476-C2a & 476-C2b & 476-C2c & 476-C2d & 476-C2e & $e x 476-C 2 a$ & $e x 476-\mathrm{C} 2 \mathrm{~b}$ & $e x 476-\mathrm{C} 2 \mathrm{c}$ & $e x 476-\mathrm{C} 2 \mathrm{e}$ \\
\hline Colonization & Yes & Yes & Yes & No & Yes & $\mathrm{NT}^{\mathrm{a}}$ & NT & NT & NT \\
\hline Cosmid & Yes & Yes & Yes & No & No & NT & NT & NT & NT \\
\hline \multicolumn{10}{|l|}{ Wild-type ORF } \\
\hline present & No & Yes & Yes & Yes & Yes & No & No & No & No \\
\hline $\mathrm{Km}^{\mathrm{r}}$ & Yes & Yes & Yes & Yes & Yes & Yes & Yes & Yes & Yes \\
\hline $\mathrm{Tc}^{\mathrm{r}}$ & Yes & Yes & Yes & Yes & No & Yes & Yes & Yes & No \\
\hline
\end{tabular}

\footnotetext{
${ }^{\mathrm{a}} \mathrm{NT}=$ not tested
} 
However, one transformant (476-C2a) also apparently lacking the wild-type ORF was able to colonize, while another transformant (476-C2d) that carried the wild-type ORF but lacked at least part of the pro operon was not. It is possible that the wild-type ORF in 476-C2a did remain functionally intact after recombination, although we were unable to detect any such event, using several primer pairs (data not shown). Interestingly, loss of the pro operon in 476-C2d suggests that this region may also be important in colonization. It encodes a glycine/betaine transporter system that is involved in osmoregulation (Cairnery et al. 1985) and may be critical for xylem colonization and signaling between the bacteria and the plant host (Matthysse and McMahan 1998).

With the full sequence of the L. xyli subsp. xyli genome about to be completed in Brazil, it is critical to have a set of molecular tools to elucidate the role, if any, individual genes play in host recognition, colonization, and disease induction in sugarcane. Identification of key genes in these various processes could lead to future control measures for this economically important disease of sugarcane. In this paper, we have demonstrated that transposon mutagenesis is one such tool, and in the future, other transposons may be selected for a saturation mutagenesis approach. Alternatively, once the genome is completed, constructs for a more targeted, markerexchange type mutagenesis can be used on selected genes. Importantly, the recombinations evidenced in the complementation study suggest that a marker selection strategy may be a valid approach for elucidation of the role that the wildtype ORF and genes play, such as in the role of the pro operon, in ratoon stunting disease.

\section{MATERIALS AND METHODS}

\section{Bacterial strains and cultures.}

Bacterial strains and plasmids are listed in Table 2. For inoculation onto sugarcane plants, both the wild-type $L$. xyli subsp. xyli and the Lxx::Tn4431 mutants were grown in 10 $\mathrm{ml}$ of modified S8 broth (Brumbley et al. 2002) containing either no antibiotics or $10 \mu \mathrm{g}$ of tetracycline per $\mathrm{ml}$, respectively. For complementation studies, $25 \mu \mathrm{g}$ of kanamycin per $\mathrm{ml}$ was also included. All cultures were grown to mid-log phase for 10 to 14 days at $28^{\circ} \mathrm{C}$ with constant shaking (150 $\mathrm{rpm}$ ). Prior to inoculation, the optical density at $560 \mathrm{~nm}$ was adjusted to between 0.5 and 0.6 with sterile $\mathrm{S} 8$ broth. L. $x y l i$ subsp. xyli cultures for transformation or genomic DNA isolation were grown as previously described (Brumbley et al. 2002). Escherichia coli strains were grown on Luria broth (LB) containing the appropriate antibiotics.

\section{Isolation and sequencing of DNA flanking the Tn4431 insertion using semispecific PCR.}

A semispecific PCR technique based on Hermann and associates (2000) was developed, using primers to each end of the transposon. Two oligonucleotide probes were designed that bound downstream from these primers. In brief, washed cell pellets from frozen Lxx::Tn4431 cell stocks were used as template. PCR was carried out using a single transposonspecific primer, bss7RM1 (5'-CTGGAAGACGGGAAGTTT CGG-3') or bsl7RM1 (5'-GCTAAAATCTGTGTTCTCTTCG G-3'). These primers are specific to each end of the transposon and are internal to the inverted terminal repeats. Amplifications were carried out in $25-\mu \mathrm{l}$ reactions containing amplification buffer (buffer $1,1.75 \mathrm{mM} \mathrm{MgCl} 2$ final concentration; Expand Long Template PCR Kit; Roche Diagnostics, Castle Hill, Australia), $250 \mu \mathrm{M}$ dNTPs, $10 \mu \mathrm{M}$ primer (bsl7RM1 or bss7RM1), and $1 \mathrm{U}$ of Taq DNA polymerase. Thermal cycling parameters were 1 cycle at $94^{\circ} \mathrm{C}$ for $5 \mathrm{~min}$, followed by 70 cycles of $30 \mathrm{~s}$ at $94^{\circ} \mathrm{C}, 15 \mathrm{~s}$ at $60^{\circ} \mathrm{C}$ (bss7RM1) or $55^{\circ} \mathrm{C}$ (bsl7RM1), $2 \mathrm{~min}$ at $72^{\circ} \mathrm{C}$, followed by a final extension step for $7 \mathrm{~min}$ at $72^{\circ} \mathrm{C}$. No template and wild-type $L$. xyli subsp. $x y l i$ isolates were used as negative controls. Amplification products were run on a $1 \%$ agarose gel, and Southern hybridization was performed essentially as described by Sambrook and associates (1989). The membrane was hybridized with either the ${ }^{33} \mathrm{P}-\gamma$-ATP labeled, transposon-specific probe bss 7 (5'-ATGCCCGGAAAACCTTAGCGTACG-3') or bsl7 (5'-AGAACACCGTTAGCTTAGCGTACG-3'). Blots were visualized after $2 \mathrm{~h}$, using a Phosphor-imager STORM 840 (Molecular Dynamics, Sunnyvale, CA, U.S.A.), following the manufacturer's instructions.

Positively hybridized PCR products were purified using MinElute columns (Qiagen, Hilden, Germany), following the manufacturer's instructions. In most instances, the remaining PCR reaction was purified, but when both hybridizing and nonhybridizing PCR products were present, the PCR reaction was electrophoresed $(0.8 \%$ agarose, $1 \times$ Tris-borate-EDTA), and the positively hybridizing DNA product was excised before purification. The purified eluate $(2 \mu \mathrm{l})$ was used for DNA sequencing using the Big-Dye Terminator kit (Perkin Elmer Applied Biosystems, Foster City, CA, U.S.A.), following the manufacturer's instructions. The oligonucleotide probes (unlabeled) were used in sequencing. Dye terminator was removed using the DyeEx96 kit (Qiagen) or the DyeEx Spin kit (Qiagen), following the manufacturer's instructions. The sequences were run on the ABI 377 automated sequencer at the Australian Genome Research Facility, Brisbane, Australia.

Table 2. Bacterial strains, cosmids, and plasmids used in this study

\begin{tabular}{|c|c|c|}
\hline Strain/plasmid & Relevant characteristics & Source or reference \\
\hline \multicolumn{3}{|l|}{ Strains } \\
\hline \multicolumn{3}{|l|}{ Escherichia coli } \\
\hline DH5a & $\begin{array}{l}\text { deoR, endA1, gyrA96, hsdR17(rk- mk+), recA1, relA1, supE44, thi-1, Delta(lacZYA- } \\
\text { argFV169), phi-80deltalacZDeltaM15, F-, Lambda- }\end{array}$ & Stratagene, La Jolla, CA, U.S.A. \\
\hline \multicolumn{3}{|l|}{ Leifsonia xyli subsp. xyli } \\
\hline QPF110 & Wild-type L.xyli subsp. xyli & Brumbley et al. 2002 \\
\hline QPF110-476 & Noncolonizng QPF110 containing a single $\mathrm{Tn} 4431$ insertion & Brumbley et al. 2002 \\
\hline $\begin{array}{l}\text { QPF110 (476-C2a, 476- } \\
\text { C2b, 476-C2c, 476- }\end{array}$ & & \\
\hline $\mathrm{C} 2 \mathrm{~d}, 476-\mathrm{C} 2 \mathrm{e})$ & Five QPF110-476 mutants harboring pLB1C2 & This study \\
\hline$e \times 476-\mathrm{C} 2 \mathrm{a}, e \times 476-\mathrm{C} 2 \mathrm{~b}$ & Four colonizno mutants reisolated from sugarcane & This stud \\
\hline \multicolumn{3}{|l|}{ Plasmids } \\
\hline pLAFR5-km & Improved broad host range cosmid cloning vector; $22.7 \mathrm{kbp} ; \mathrm{RP} 4$ Ori; $\mathrm{Km}^{\mathrm{r}}$ & Brumbley et al. 2002 \\
\hline pBluescript II SK+ & Phagemid cloning vector; $2.9 \mathrm{kbp}$; ColE1 Ori; $\mathrm{Ap}^{\mathrm{r}}$ & Stratagene, La Jolla, CA, U.S.A. \\
\hline pLB1D6 & Cosmid vector containing L.xyli subsp. xyli genomic fragment; $45 \mathrm{kbp} ; \mathrm{RP} 4$ Ori; $\mathrm{Km}^{\mathrm{r}}$ & This study \\
\hline pLB1C2 & Cosmid vector containing L.xyli subsp. xyli genomic fragment; $45 \mathrm{kbp}$; RP4 Ori; $\mathrm{Km}^{\mathrm{r}}$ & This study \\
\hline
\end{tabular}


Analysis of DNA sequence.

Identification of regions into which $\mathrm{Tn} 4431$ inserted was performed using BlastX v. 1.4 .9 (Altschul et al. 1990; Gish and States 1993) against the NR Bacterial GenPept database compiled by the Australian National Genomic Information Service (ANGIS, Sydney, Australia). Relative positions of Tn4431 insertion into the L. xyli subsp. xyli genome were identified using BlastN v. 2.1.2 (Altschul et al. 1997) against the contig databases of the L. xyli subsp. xyli Genome Sequencing Project (AEG, Piracicaba, Brazil). Raw sequence data was analyzed in MacVector 6.5.3 (Accelrys, San Diego, CA, U.S.A.) and ContigExpress (InforMax, Bethesda, MD, U.S.A.), and contiguous sequences were assembled using AssemblyLIGN 1.0.9b (Accelrys, Cambridge). BlastN, BlastX, and BlastP (Altschul et al. 1990) searches were carried out using the NR nucleic, bacteria, and Mycobacterium tuberculosum databases (ANGIS).

\section{Colonization and complementation assay.}

To screen the $L x x:: \operatorname{Tn} 4431$ mutants for loss of colonization, stem sections containing one bud (one-eye set) of sugarcane cultivar Q110 were grown in steam-sterilized soil in $15-\mathrm{cm}$ pots for 6 weeks. The tops of these plants were chopped off above the apical meristem, and a $100-\mu \mathrm{l}$ drop of a suspension of the Lxx::Tn4431 mutants, wild-type L. xyli subsp. xyli cells, or xylem extract from $L$. xyli subsp. xyli-infected sugarcane plants of cultivar Q110 was immediately placed on the cut surface. All inoculations were performed in triplicate. After three months, the plants were harvested by cutting them off just above the soil line. The tops and leaves were removed and discarded, and the fibrovascular fluid was extracted using positive pressure. The presence of $L$. xyli subsp. xyli wild-type and Lxx::Tn4431 mutants in the fibrovascular fluid was determined by evaporative binding enzyme immunosorbent assay (Croft et al. 1994). Any $L x x:$ Tn4431 mutants unable to colonize sugarcane after three attempts were reinoculated a fourth time with 15 replicates.

To screen $L x x:$ Tn4431 mutant for complementation, either the inoculation method described above was used or an alternative technique using two-eye sets of sugarcane cultivar Q110 was employed. Two-eye sets were inoculated with $L$. xyli subsp. xyli in S8 broth supplemented with filter-sterilized fibrovascular fluid from healthy Q110 plants $24 \mathrm{~h}$ prior to inoculation. Inoculation was performed by submersion of twoeye sets in cell suspensions for $5 \mathrm{~min}$. Following inoculation, sets were planted in $20-\mathrm{cm}$ plastic pots and were grown in glasshouses for three months. All inoculations were performed in triplicate. Plants were harvested, and fibrovascular fluid was extracted and analyzed for the presence of L. xyli subsp. xyli as described above.

\section{Isolation and sequencing of flanking DNA from Lxx::Tn4431 mutant QPF110-476.}

Isolation of genomic DNA from L. xyli subsp. xyli was done as previously described (Brumbley et al. 2002). DNA $(1.5 \mu \mathrm{g})$ from $L x x:$ Tn4431 mutant QPF110-476 was digested with 20 $\mathrm{U}$ of $P s t \mathrm{I}$ and, of this, $1 \mu \mathrm{g}$ was religated using $8 \mathrm{U}$ of $\mathrm{T}_{4}$-DNA ligase. Following phenol-chloroform extraction and ethanol precipitation, ligated DNA was resuspended in $50 \mu \mathrm{l}$ of water. Of this, $1 \mu \mathrm{l}$ was used as template. Using primers bsl3 (5'CGTCCTCAGTGTCTGCTCTTCG-3') and bsl7 (5'-AGAAC ACCGTTAGCTTAGCGTACG-3'), which were designed from sequence data from the large EcoRI/PstI fragment of Tn4431, inverse PCR was performed under the following conditions: $0.26 \mathrm{mM}$ dNTP, $0.1 \mu \mathrm{M}$ primers, $3 \mathrm{mM} \mathrm{Mg}^{2+}, 0.5 \times \mathrm{Q}$-solution, $0.5 \mathrm{U}$ of Taq DNA polymerase (Qiagen) in $25 \mu \mathrm{l}$ reactions. The PCR profile was: $95^{\circ} \mathrm{C}$ for $5 \mathrm{~min}, 35$ cycles of $94^{\circ} \mathrm{C}$ for 1 $\min , 54^{\circ} \mathrm{C}$ for $30 \mathrm{~s}$, and $70^{\circ} \mathrm{C}$ for $1 \mathrm{~min}$, a final extension step of $70^{\circ} \mathrm{C}$ for $10 \mathrm{~min}$, and indefinite hold at $4^{\circ} \mathrm{C}$. PCR products were digested with PstI and EcoRI and were cloned into pBluescript SK II+ (Stratagene, La Jolla, CA, U.S.A.). Correct flanking DNA was confirmed by Southern hybridization against genomic DNA from wild-type and mutant L. xyli subsp. xyli, using the inverse PCR product as a probe.

A cosmid library was generated from wild-type strain QPF110 by partially digesting $3 \mu \mathrm{g}$ of $L$. xyli subsp. xyli genomic DNA with Sau3AI, followed by ligation into BamHIcut pLAFR5-Km (Brumbley et al. 2002) for $4 \mathrm{~h}$ at $22^{\circ} \mathrm{C}$. Following phenol extraction and ethanol precipitation, ligation products were packaged, using Gigapack II XL according to the supplier's instructions (Stratagene). A total of 1,920 colonies were picked and inoculated into 96-well microtiter dishes containing LB with $10 \mu \mathrm{g}$ of tetracycline per $\mathrm{ml}$ and $50 \mu \mathrm{g}$ of kanamycin per $\mathrm{ml}$ and were grown overnight at $37^{\circ} \mathrm{C}$. Sterile glycerol was added to a final $\mathrm{vol} / \mathrm{vol}$ of $12 \%$, prior to storage at $-80^{\circ} \mathrm{C}$. The genomic library was plated onto Hybond $\mathrm{N}+$ membranes (Amersham, Little Chalfont, U.K.) and was grown on LB agar containing $10 \mu \mathrm{g}$ of tetracycline per $\mathrm{ml}$ and $50 \mu \mathrm{g}$ of kanamycin per ml. Colony hybridization was performed as described by Sambrook and associates (1989), using ${ }^{32} \mathrm{P}$-labeled flanking DNA, prepared using the Rediprime system (Amersham) in accordance with supplier's instructions. Cosmids with homology to flanking DNA were shotgun cloned into pBluescript SK II+ and were sequenced as described above. Direct sequencing of cosmids using primers designed from previously determined data closed remaining gaps.

\section{Complementation of $L$. xyli subsp. xyli mutant 476.}

Lxx::Tn4431 mutant QPF110-476 was transformed with cosmid (pLB1C2) containing the complementary DNA from wild-type L. xyli subsp. xyli strain QPF110 as described (Brumbley et al. 2002). Transformants confirmed to be resistant to kanamycin were analyzed for the presence of the cosmid by Southern hybridization and PCR. Southern hybridization was carried out essentially as described by Brumbley and associates (2002). In summary, total genomic DNA $(10 \mu \mathrm{g})$ from $L . x y l i$ subsp. xyli QPF110, QPF110-476 Tn4431 mutant (476), and transformants containing the complementary cosmid clone pLB1C2 (C2a to $\mathrm{C} 2 \mathrm{e})$ were digested with Pst I and probed with a $2.1-\mathrm{kbp}{ }^{32} \mathrm{P}$-labeled EcoRI/PstI fragment from DNA flanking the Tn4431 insertion. PCR analysis was carried out to confirm the presence of the mutant and wild-type ORF. The mutant ORF was identified using primer pairs bs17RM1 and ORF24F (5'ATGTGTGCGCCGGGGGAGGCTGGTTCA-3') and bss7RM1 and ORF24R (5'-CTCCTGCGCCTGCTGAGCTCACCGCT$3^{\prime}$ ), which amplify across the $L$. xyli subsp. xyli genome:: Tn4431 fusion. The wild-type ORF carried on the cosmid was confirmed using primers ORF24F and ORF24R. PCR products were separated on a $1 \%$ agarose gel.

Five positive transformants were inoculated into sugarcane, as described above. After three months, fibrovascular fluid was extracted from plants and spread onto filters as described (Brumbley et al. 2002). Single bacterial colonies were restreaked twice and were stored at $-80^{\circ} \mathrm{C}$. PCR analysis was carried out again to confirm the presence of the mutant and wild-type sequences.

\section{ACKNOWLEDGMENTS}

Funding for this activity was provided by the Australian sugar industry and the Commonwealth Government through the Sugar Research and Development Corporation and from the Queensland State Government through the Department of Primary Industries and is gratefully acknowledged. 


\section{LITERATURE CITED}

Altschul, S. F., Gish, W., Miller, W., Myers, E. W., and Lipman, D. J. 1990. Basic local alignment search tool. J. Mol. Biol. 215:403-410.

Altschul, S. F., Madden, T. L., Schäffer, A. A., Zhang, J., Xhang, Z., Miller, W., and Lipman, D. J. 1997. Gapped BLAST and PSI-BLAST: A new generation of protein database search programs. Nucleic Acids Res. 25:3389-3402.

Bailey, R. A., and Bechet, G. R. 1997. Further evidence of the effects of ratoon stunting disease on production under irrigated and rain fed conditions. Pages 97-101 in: Proceedings of the 71st Meeting of the South African Sugar Technology Association, Durban and Mount Edgecombe, South Africa.

Bolotin, A., Mauger, S., Malarme, K., Dusko Ehrlich, S. and Sorokin, A. 1999. Low-redundancy sequencing of the entire Lactococcus lactis IL1403 genome. Antonie van Leeuwenhoek 76:27-76.

Brumbley, S. M., Petrasovits, L. M., Birch, R. G., and Taylor, P. W. J. 2002. Transformation and transposon mutagenesis of Leifsonia xyli subsp. $x y l i$, causal organism of ratoon stunting disease of sugarcane. Mol. Plant-Microbe Interact. 15:262-268.

Cairnery, J., Booth, I. R., and Higgins, C. F. 1985. Osmoregulation of gene expression in Salmonella typhimurium: proU encodes an osmotically induced betaine transport system. J. Bacteriol. 164:12241232.

Croft, B. J., Greet, A. D., Leaman, T. M., and Tealke, D. S. 1994. RSD diagnosis and varietal screening in sugarcane using the EB-EIA technique. Pages 143-151 in: Proceedings of the 16th Meeting of the Australian Society of Sugarcane Technologists, Townsville, Queensland, Australia.

Davies, C. J., and Hutchison, C. A. 1995. Insertion site specificity of the transposon Tn3. Nucleic Acids Res. 23:507-514.

Davis, M. J., Gillaspie, A. G., Harris, R. W., and Lowson, R. H. 1980. Ratoon stunting disease of sugarcane: Isolation of the causal bacterium. Science 210:1365-1367.

Davis, M. J., Gillaspie, A. G., Jr., Vidaver, A. K., and Harris, R. W. 1984. Clavibacter: a new genus containing some phytopathogenic coryneform bacteria, including Clavibacter xyli subsp. xyli sp. nov., subsp. nov. and Clavibacter xyli subsp. cynodontis subsp. nov., pathogens that cause ratoon stunting disease of sugarcane and Bermuda grass stunting disease. Int. J. Syst. Bacteriol. 34:107-117.

Evtushenko, L., Dorofeeva, L., Subbotin, J., and Tiedje, J. 2000. Leifsonia poae gen. nov., sp. nov., isolated from nematode galls on Poа апnиа, and reclassification of 'Corynebacterium aquaticum' Leifson 1962 as Leifsonia aquatica (ex Leifson 1962) gen. nov., nom. rev., comb. nov. and Clavibacter xyli Davis et al. 1984 with two subspecies as Leifsonia xyli (Davis et al. 1984) gen. nov., comb. nov. Int. J. Syst. Evol. Microbiol. 50:371-380.
Gattiker, A., Gasteiger, E., and Bairoch, A. 2002. ScanProsite: A reference implementation of a PROSITE scanning tool. Applied Bioinformatics 1:107-108.

Giglioti, E. A., Comstock, J. C., Davis, M. J., Matsuoka, S., and Tokeshi, H. 1999. Combining tissue blot enzyme immunoassay and staining by transpiration methods to evaluate colonization of sugarcane stalks by Clavibacter xyli subsp. xyli and its effects on xylem functionality. Grupo Paulista de Fitopatologia 25:125-132.

Gillaspie, A. G., and Teakle, D. S. 1989. Ratoon stunting disease. Pages 59-80 In: Diseases of Sugarcane: Major Diseases. C. Ricaud, B. T. Egan, A. G. Gillaspie, Jr., and C. G. Hughes, eds. Elsevier Science Publishing, Inc., New York.

Gish, W., and States, D. J. 1993. Identification of protein coding regions by database similarity search. Nature Genet. 3:266-272.

Hermann, S. R., Miller, J. A. C., O’Neill, S., Tsao, T. T., Harding, R. M., and Dale, J. L. 2000. Single-primer amplification of flanking sequences. BioTechniques 29:1178-1180.

Kao, J., and Damann, K. E. 1980. In situ localization and morphology of the bacterium associated with ratoon stunting disease of sugarcane. Can. J. Botany 58:310-315.

Koike, H., Gillaspie, A. G., Jr., and Benda, G. T. A. 1982. Cane yield response to ratoon stunting disease. Int. Sugar J. 84:131-133.

Mahillon, J., and Chandler, M. 1998. Insertion sequences. Microbiol. Mol. Biol. Rev. 62:725-774.

Matthysse, A. G. and McMahan, S. 1998. Root colonization by Agrobacterium tumefaciens is reduced in $c e l$, at $\mathrm{B}$, att $\mathrm{D}$, and att $\mathrm{R}$ mutants. Appl. Environ. Microbiol. 64:2341-2345.

McDougall, W. A., Steindl, D. R. L., and Elliot, J. T. 1948. Variations in primary vigour in the variety Q28. Cane Growers' Q. Bull. 12:31-34.

Rossler, L. A. 1974. The effects of ratoon stunting disease on three sugarcane varieties under different irrigation regimes. Pages 250-257 in: Proceedings of the 15 th Meeting of the International Society of Sugar Cane Technologists, Durban, South Africa.

Ross-Macdonald, P., Sheehan, A., Roeder, G. S., and Snyder, M. 1999. Large-scale analysis of the yeast genome by transposon tagging and gene disruption. Nature. 402:413-418.

Sambrook, J., Fritsch, E. F., and Maniatis, T. 1989. Molecular Cloning: A Laboratory Manual. 2nd ed. Cold Spring Harbor Laboratory Press, Cold Spring Harbor, NY, U.S.A.

Shaw, J. J., Settles, L. G., Kado, C. I. 1988. Transposon Tn4431 mutagenesis of Xanthomonas campestris pv. campestris: Characterization of a nonpathogenic mutant and cloning of a locus for pathogenicity. Mol. Plant-Microbe Interact. 1:39-45.

Steib, R. J., and Chilton, S. J. P. 1968. The role of ratoon stunting disease in the determination of sugarcane varieties. Sugar J. 30:10-12.

Wismer, C. A. 1971. A sugarcane clone apparently immune to RSD. Sugarcane Pathologists Newsl. 6:46. 